\title{
A BRINCADEIRA NO CONTEXTO ESCOLAR: UM RECURSO DE SOCIALIZAÇÃO
}

Nathalia Franco Alves, Michelle Dias Luccas, Leonardo Orlandi, Márcia Regina Canhoto de Lima, José Milton de Lima

Universidade Estadual Paulista - UNESP, curso de Educação Física, Presidente Prudente, SP. E-mail: nathalia fa@hotmail.com. PIBIC-CNPQ

\section{RESUMO}

A presente pesquisa discute a brincadeira no contexto escolar amparada pelos autores da Sociologia da Infância. Assumimos como objetivos entender quais eram as compreensões das professoras sobre brincadeira, como esse entendimento é externalizado na prática pedagógica e na rotina escolar e, ainda, como as crianças se socializavam a partir do brincar. A investigação contou com a participação de duas escolas parceiras, na periferia da cidade de Presidente Prudente/SP, totalizando 54 crianças da Educação Infantil e duas professoras. Tratou-se de uma pesquisa qualitativa do tipo etnográfica, que caminha juntamente com a observação participante. Como resultados observou-se que ambas as professoras compreendem a necessidade da brincadeira no universo infantil, no entanto, apenas uma a utiliza em suas práticas, o que nos impulsiona a continuar as pesquisas. Em relação às crianças, notou-se uma melhor socialização a partir das vivências lúdicas.

Palavras chave: Criança, Ludicidade, Fantasia, Infância, Brincadeira.

\section{THE JOKE IN THE SCHOOL CONTEXT: A FORM OF SOCIALIZATION}

\begin{abstract}
The research discusses the joke in the school context supported by the authors of the sociology of childhood. The goals seek to understand what the understanding obtained by teachers about joke, as this understanding is outsourced in pedagogical practice and school routine and how children socialize from the play. With the participation of two partner schools, on the outskirts of the city of Presidente Prudente, with 54 children in early childhood education, I and II and two teachers. It is a qualitative research of the ethnographic type who walks along with the participant observation. As a result we have to both teachers understand the need of the joke in the infant universe, however, only one of the uses in their practices, which urges us to continue the research. Regarding children, noticed a better socialization from the playful experiences.
\end{abstract}

Keywords: Child, Playfulness, fantasy, childhood, joke. 
INTRODUÇÃO

O presente artigo "A brincadeira no contexto escolar: um recurso de socialização" apresenta resultados da pesquisa de iniciação científica intitulada: A ludicidade como eixo estruturador das Culturas da Infância: dando voz às crianças. Partimos do pressuposto de que há pouca compreensão e aplicação da brincadeira nas práticas da Educação Infantil e que essa temática é relevante a partir dos estudos e análises do desenvolvimento infantil por meio da brincadeira. Vale destacar que a pesquisadora participa do CEPELIJ (Centro de Estudo Pesquisa, Educação, Ludicidade, Infância, Juventude), situado na Faculdade de Ciências e Tecnologia, Universidade Estadual Paulista UNESP, Campus de Presidente Prudente/SP. A pesquisa contou com a participação de duas escolas da periferia da cidade, totalizando 54 crianças e duas professoras.

Apresentaremos a discussão que esclarece parte do contexto histórico da infância e descreve o que é ludicidade, baseados nos estudos da Sociologia da Infância, que concebe essa etapa da vida como uma categoria social.

A sociologia da infância propõe-se a interrogar a sociedade a partir de um ponto de vista que toma as crianças como objecto de investigação sociológica por direito próprio, fazendo acrescer o conhecimento, não apenas sobre infância, mas sobre o conjunto da sociedade globalmente considerada. (SARMENTO, 2005, p. 361).

A investigação estabeleceu como objetivos centrais analisar como a brincadeira é trabalhada dentro do contexto escolar e qual a compreensão das professoras sobre a temática. Acerca das crianças, buscou-se observar em quais situações elas atuam como protagonistas e como ocorrem as interações com seus pares e professoras.

\section{MÉTODOS}

Por não se priorizar os dados estatísticos, adotou-se como metodologia, a pesquisa qualitativa do tipo etnográfica, que no caso em questão, caminha juntamente com a observação participante. Segundo Agrosino (2008 p.17), a observação participante é "um modo de pesquisar que coloca o pesquisador no meio da comunidade que ele esta estudando".

Os estudos etnográficos caracterizam-se, primeiramente, pelo envolvimento do pesquisador no ambiente natural da pesquisa, exigindo uma observação e uma interpretação holística dos dados coletados, ou seja, no âmbito da totalidade das ações humanas. Os dados coletados podem ser em forma de narrativas ou história de vida, mas sem jamais perder o ponto chave da etnografia que é descrição densa e contextualizada do fenômeno pesquisado. (SILVA et al, 2010, p. 6). 
Nesse sentido, a etnografia refere-se ao adentro do pesquisador no contexto que se quer estudar, participando e compartilhando de todas as suas vivências. Caracterizamos a presente pesquisa como do tipo etnográfica pelo tempo semanal reduzido que o pesquisador tem no ambiente escolar, não o deixando diariamente em convívio com as crianças. Os investigadores contam com reuniões semanais referentes a discussões relacionadas aos autores da Sociologia da Infância, relato das vivências, troca de informações e experiências. Além destas reuniões, ocorre, quinzenalmente, o encontro do Grupo de Pesquisa: Cultura Corporal Saberes e Fazeres, coordenados por três professores doutores que propõem estudos de textos e aperfeiçoamento da pesquisa científica. As observações acontecem uma vez por semana e tem duração de cinquenta minutos. Os dados são cuidadosamente analisados e anotados em diários de campo, contando como métodos da pesquisa: as entrevistas, os desenhos, as fotografias e os vídeos. A pesquisa está sustentada no Protocolo do Comitê de Ética em Pesquisa (CEP) da Plataforma Brasil, número: CAAE 134242138.0000 .5402$.

\section{RESULTADOS}

Em primeiro aparato, respondendo aos objetivos já esclarecidos, mostraremos a concepção das professoras sobre o que é ludicidade e como a utilizam em suas práticas. Por questões éticas não mencionaremos seus nomes verídicos, chamando-as de Lucélia e Celinha, respectivamente. Ambas trabalham com a mesma faixa etária e são regidas pela mesma direção e coordenação, porém a postura adotada pelas duas é divergente. Verificamos que Lucélia desde o início das intervenções, mostrou-se disposta a interagir com as crianças, em todas as atividades e teve participação direta, entrando no mundo da imaginação e permitindo um contato maior com os alunos.

Durante o processo, as educadoras foram entrevistadas a partir de questões elaboradas pela bolsista, com o auxílio de um gravador de áudio. As professoras sabiam que estavam sendo entrevistadas e gravadas. Posteriormente, os diálogos foram cuidadosamente analisados, mostrando-nos que a professora Lucélia, mesmo apresentando certa discrepância conceitual, compreende a importância que o lúdico tem no desenvolvimento infantil e busca tê-lo em suas práticas, utilizando-o como recurso pedagógico, tornando mais eficaz a compreensão dos conteúdos.

A professora Celinha demonstrou entendimento acerca da necessidade da ludicidade que, segundo ela, utiliza em suas aulas e no seu cronograma diário. No entanto, a mesma não participa das atividades por nós observadas. A turma sempre fica nas atividades enquanto ela avalia alguns 
trabalhos, organiza pastas e resolve outras necessidades internas em sala de aula. Quando aceita acompanha-los até a quadra, fica na maioria das vezes utilizando o celular ou conversando com algum outro profissional ali presente.

Entendem-se as dificuldades que as educadoras encontram no momento da junção do lúdico com os materiais apostilados, porém, se não é lhes dado esse aparato, necessário é que se trabalhe com a própria imaginação e acrescentem elementos atrativos para as crianças, ligando o que Ihe é dado como objeto de ensino, com a bagagem lúdico educativa que se carrega, ou seja, unir seus saberes pedagógicos com elementos da ludicidade.

Consideramos que em pesquisas com crianças, torna-se necessário à conquista dos pequenos, obtendo a permissão para análise de seu cotidiano, de sua cultura. Não é interessante uma observação forçada. A criança precisa se sentir à vontade com o adulto e permitir que ele esteja ali. Nesse sentido, vemos que é necessária uma relação de socialização entre adultos e crianças. É através da socialização que as crianças vão descobrindo as próprias especificidades, como também as compartilhando com seus pares.

Quando assumimos a pesquisa, propomos uma conversa com elas a fim de conhecê-las, entendendo quais eram os brinquedos e brincadeiras que mais gostavam e esperavam ter. No intuito de atingir este propósito, os colaboradores levaram histórias que exploraram a fantasia e, a partir delas, puderam constituir um diálogo com as crianças.

Foram trabalhadas brincadeiras como circuitos compostos de: teatros, músicas, jogos de coordenação, entre outros. É importante ressaltar que uma das salas pesquisadas participa desde o maternal de intervenções lúdicas realizadas por bolsistas de extensão do CEPELIJ. A diferença entre essa sala com a outra é grande. As crianças tiveram uma melhora em seu desenvolvimento psicomotor, mostrando-se mais cooperativas, socializadas e atentas com as atividades, inclusive as realizadas em sala de aula.

\section{DISCUSSÃO}

A brincadeira no contexto infantil está diretamente relacionada com o desenvolvimento das crianças. Crianças brincam desde sempre, no entanto, a concepção da importância dessa relação é ressaltada com os pressupostos da Sociologia da Infância.

No período medieval, as crianças eram vistas como adultos em miniatura, a brincadeira não era encarada como parte dos infantes, não havia uma compreensão adequada dos cuidados necessários nessa etapa da vida. No final do século XVI e início do século XVII, segundo Ariès (1981), esses ideais tomaram outra perspectiva. 
Com o desenvolvimento do capitalismo, a sociedade foi dividida em duas esferas: a pública, sendo administrada pelos poderes estatais e a privada, que tinha por responsável a família, que segundo Santos (2008), cuidava das necessidades básicas da criança, como a higiene e relação afetiva. Santos (2008) traz o conceito de criança bem educada, definindo-a como alguém com direitos e sem participações nos contextos rudes e adultos. Essa perspectiva, no principio de suas ideias, cabia às crianças burguesas, somente no século XVII seu olhar foi direcionado para as camadas menos favorecidas da sociedade. "Mais tarde, com o desenvolvimento do capitalismo, essa noção é direcionada à criança das classes populares, buscando educá-la para ser um adulto útil e produtivo". (SANTOS, 2008, p.116).

A Sociologia da Infância traz a concepção de Culturas da Infância, definida por Sarmento (2003) como o conjunto de ações e particularidades pertencentes aos pequenos. "[...] A capacidade das crianças em construírem de forma sistematizada modos de significação do mundo e de ação intencional, que são distintos dos modos adultos de significação e ação." (SARMENTO, 2003, p.4).

Entendemos o imaginário infantil como a capacidade da criança se expressar, instituir elementos que impulsionem suas vivências, sejam eles desejados em pertencerem aos seus meios, como também uma reprodução de seu cotidiano. Sobre esse fenômeno, relacionamos o nome dado por Corsaro (2002): Reprodução Interpretativa entendida como a capacidade em reproduzir os contextos participados introduzindo neles elementos que os deixem mais significativos.

A abordagem interpretativa considera a socialização como um processo produtivo-reprodutivo, de densidade crescente e de reorganização do conhecimento que muda com o desenvolvimento cognitivo e com competências linguísticas das crianças e com as mudanças nos seus mundos sociais. (CORSARO, 2002, p. 114).

Encontramos dentro das Culturas da Infância, ditos pro Sarmento (2003), quatro eixos que estruturam o relacionamento das crianças, sendo estes: Interactividade, Reiteração, Fantasia do Real e Ludicidade.

A Interactividade engloba a capacidade de envolvimento das crianças com seus pares. A cultura de pares é explicada por Corsaro (2009), como a relação tida entre as crianças.

A Reiteração refere-se ao tempo diferenciado da criança. A infância não se apodera do tempo cronológico, mas sim do recursivo ${ }^{1}$. Capacita-se aqui a função de dar continuidade no que já foi terminado, sendo assim chamado de plano sincrônico².

\footnotetext{
${ }^{1}$ Recursivo: Segundo Ferreira (2008) é o que se pode repetir até o infinito.

${ }^{2}$ Sicrônico: Segundo Ferreira (2008) é o que se realiza ao mesmo tempo que outra atividade. 
A Fantasia do real é a capacidade imaginativa da criança. A capacidade dos pequenos em explorar o seu "faz de conta", palavras estas que são cuidadosamente tratadas pelo autor como as competências em reinventar o contexto em que se vive, inserindo nele elementos figurativos que o deixe mais próximo do esperado pela criança; além de ser uma oportunidade de ela trazer para a realidade personagens fictícios. É o momento que ela cria o seu mundo.

A Ludicidade é eixo norteador referência para esta pesquisa, com toda a sua complexidade determina-se no que a criança tem de mais significativo, o brincar. Ao falar-se em brincadeira, remete quase imediatamente à criança, porém, tal prática também está presente nos adultos.

Brincar não é exclusivo das crianças, é próprio do homem e uma das suas atividades sociais mais significativas. Porém, as crianças brincam contínua e abnegadamente. Contrariamente aos adultos, entre brincar e fazer coisas sérias não há distinção, sendo o brincar muito do que as crianças fazem de mais sério. (SARMENTO, 2004, p.15).

A brincadeira não deve ser estigmatizada como prática de distração. Suas inúmeras contribuições permitem o aprendizado e reconhecimento de valores, em qualquer faixa etária.

Para as crianças, a brincadeira é uma forma privilegiada de interação com outros sujeitos, adultos e crianças, e com os objetos e a natureza à sua volta. Brincando, elas se apropriam criativamente de formas de ação social tipicamente humanas e de práticas sociais específicas dos grupos aos quais pertencem, aprendendo sobre si mesmas e sobre o mundo em que vivem. Se entendermos que a infância é um período em que o ser humano está se constituindo culturalmente, a brincadeira assume importância fundamental como forma de participação social e como atividade que possibilita a apropriação, a ressignificação e a reelaboração da cultura pelas crianças. (BORBA, 2007, p. 12).

As crianças de 0 a 6 anos estão entrando cada vez mais cedo no universo escolar, e na contemporaneidade, os pais, muito atarefados pelo trabalho, passam menos tempo com elas, desta forma a escola se tornou o lugar de encontro com seus pares, e onde podem expressar as suas culturas, sendo assim, o lugar responsável também pela sua formação integral.

A criança, ao contrário do que o adultocentrismo prega, é um ser autônomo, entretanto, ela não é independente do adulto. Mesmo a Sociologia da Infância compreende a necessidade que ela tem em se relacionar com a categoria social adulta para conseguir se desenvolver.

Todavia as crianças não produzem culturas num vazio social, assim como não têm completa autonomia no processo de socialização. Isso significa considerar que elas têm uma autonomia que é relativa, ou seja, as respostas e reações, os jogos sociodramáticos, as brincadeiras e as interpretações da realidade são 
também produtos das interações com adultos e crianças. (DELGADO e MULLER, 2005, p. 164).

Considerando os dizeres acima, entendemos que a participação adulta na vida da criança é essencial. É preciso alguém que os oriente e os instrua sobre como proceder em suas ações. $O$ professor é, portanto, responsável pela criança, assim como pela sua educação formal. Com isso, a sua união com o brincar é indispensável, precisando de uma maior interação com esse contexto. "O profissional precisa aumentar a criatividade, o entusiasmo, a alegria e observar as crianças no decorrer do brincar. É necessário que o educador entenda o brincar da criança" (VOLPINI e TEIXEIRA, 2014, p.85). Segundo Muzel (2006), as crianças não chegam à escola vazias e ainda dividem o mesmo espaço com o adulto, professores neste caso, que se dividem também nas funções de ensinante e de aprendiz, quando a criança pode também ensinar ao professor seu repertório lúdico e este o ajudar a enriquecê-lo.

\section{CONCLUSÃO}

Dar voz a criança é entendê-la em todas as suas formas de agir, em suas falas, atitudes e gestos. Criança é muito mais do que um "Receptáculo Passivo", ela é protagonista ativa de seu universo. É cuidada, aprende com o adulto sim, mas necessita, também, de liberdade e reconhecimento para que consiga se desenvolver no mundo. Não apenas repete o que lhes é passado, elas se apropriam desses saberes e criam aos poucos a sua personalidade.

A Criança tem uma vida particular, e nós, como estudantes e futuros professores, precisamos nos empenhar para que esse universo seja investigado e compreendido. Temos que dar espaço para essa realidade. A fantasia não pode acabar. A brincadeira não pode acabar. E cabe a nós colocá-las em foco nas nossas experiências, aprendendo sobre o que há mais precioso e fértil no universo infantil.

\section{REFERENCIAS}

AGROSINO, Michael; FONSECA, Tradução José. Etnografia e observação participante. Porto Alegre: Atmed - Sa, 2009. 138 p.

ARIÈS, P. O sentimento da Infância. In: História social da criança e dafamília. 2ed. Rio de Janeiro: LTC Editora, 1981, p.29- 164.

BORBA, A. M. A brincadeira como experiência de cultura na Educação Infantil. Revista Criança do Professor de Educação Infantil, n. 44, v. 3 p. 12-14, nov. 2007. 
CORSARO, William A.. A reprodução Interpretativa no brincar ao faz de conta das crianças;. Educação, Sociedade e Culturas., n. 17, p.113-134, fev. 2002.

DELGADO, Ana Cristina Coll; MULLER, Fernanda. Em busca de metodologias investigativas com as crianças e suas culturas. Cadernos de Pesquisa, v. 35, n. 125, p.161-179, Mar/Ago2005.

FERREIRA, Aurélio Buarque de Holanda. Dicionário Aurélio Básico da Língua Portuguesa. Rio de Janeiro: Nova Fronteira, 2008, p. 214.

MUZEL, Andrei Alberto. Reflexões sobre a Produção Cultural na Infância, Itapeva, p.1-10, jan. 2008.

SANTOS, NIS. Historiar sobre a vida na escola faz sentido: análise discursiva de textos escritos por alunos de uma escola pública. SILVEIRA, AF.,et al., org. Cidadania e participação social. Rio de Janeiro: Centro Edelstein de Pesquisas Sociais, 2008. pp. 115-133.

SARMENTO, Manuel Jacinto. As Culturas da Infância nas encruzilhadas da $\mathbf{2}^{\circ}$ Modernidade. Instituto de Estudos da Criança, Universidade do Minho, Portugal, p.1-22, 2003. http://dx.doi.org/10.1590/S0101-73302005000200003

SARMENTO, Manuel Jacinto. Gerações e alteridade: interrogações a partir da sociologia da infância. Educação Social, Campinas, v. 26, n. 91, p.361-378, 2005.

SILVA, Maria Oneide Lino da et al. Sandra Suely Oliveira: Vanderléia Andrade Pererira, Maria da Glória Soares Barbosa Lima. Etnografia e Pesquisa Qualitativa: Apontamentos Sobre Um Caminho Metodológico de Investigação. Piaui, p. 1-13. 2010.

TEIXEIRA, Hélita Carla; VOLPINI, Maria Néli. A importância do brincar no contexto da Educação Infantil: creche e pré-escola. Disponível em: <http://unifafibe.com.br/revistasonline/arquivos/cadernodeeducacao/sumario/31/040420140740 01.pdf>. Acesso em: 1 jan. 2014. 